\title{
Experimental study on dehumidification performance of liquid desiccant system with aqueous $\mathrm{HCO}_{2} \mathrm{~K}$ solution
}

\section{DOI : 10.36909/jer.ICIPPSD.15533}

\author{
Ijas Ahmed.M, Amulya Yatelly*, Gangadhara Kiran Kumar L*
}

*Department of Management Engineering, NIT Calicut, Kerala, India.

*Email: ganga@nitc.ac.in; Corresponding Author.

\begin{abstract}
The liquid desiccant systems are one of the promising technologies in dehumidification applications. The experimental study on dehumidification performance of a counter flow structured packing liquid desiccant system is done with Aqueous $\mathrm{HCO}_{2} \mathrm{~K}$ as working fluid. The $\mathrm{HCO}_{2} \mathrm{~K}$ solution at different mass flow rate of air and solution is tested. The airflow rate is varied from $0.187 \mathrm{~kg} / \mathrm{s}$ to $0.272 \mathrm{~kg} / \mathrm{s}$ and the solution flow rate is varied from 0.053 to $0.115 \mathrm{~kg} / \mathrm{s}$. The output parameters, specific moisture change, moisture removal rate, dehumidification effectiveness and latent heat removal capacity varied in following ranges 3-4.2 g/kg of dry air, 2.4$3.1 \mathrm{~kg} / \mathrm{h}, 0.12-0.21$ and $1.7-2.1 \mathrm{~kW}$ respectively. Particularly when air flow rate increases from $0.187 \mathrm{~kg} / \mathrm{s}$ to $0.272 \mathrm{~kg} / \mathrm{s}$ the moisture removal performance improves about $11 \%$ whereas when the solution flow rate increases from 0.055 to $0.115 \mathrm{~kg} / \mathrm{s}$, improvement in moisture removal performance about 20\%. The results imply that increase in solution flow rate always have the positive impact on dehumidification performance. The increase in airflow rate has the

negative impact on specific moisture removal and effectiveness, but the impact is positive in case of the moisture removal rate and latent heat removal capacity. The Overall results show a promising dehumidification performance and further improvement is possible by incorporating a cooling system.
\end{abstract}

Keywords: Liquid desiccant, Dehumidification, Potassium formate $\left(\mathrm{HCO}_{2} \mathrm{~K}\right)$ 


\section{NOMENCLATURE}

$\begin{array}{cl}w_{\text {in }} & \begin{array}{l}\text { Air humidity ratio at entry of the dehumidifier } \mathrm{g} / \mathrm{kg} \text { of } \\ \text { dry air }\end{array} \\ w_{\text {out }} & \begin{array}{l}\text { Air humidity ratio at exit of the dehumidifier in } \mathrm{g} / \mathrm{kg} \text { of } \\ \text { dry air }\end{array} \\ w_{\text {eq }} & \begin{array}{l}\text { Equilibrium humidity ratio of the water vapour in liquid } \\ \text { desiccant } \mathrm{g} / \mathrm{kg}\end{array} \\ \dot{m}_{\text {air }} & \text { mass flow rate of air in } \mathrm{kg} / \mathrm{s} \\ T_{\text {sol }} & \text { Temperature of solution in }{ }^{\circ} \mathrm{C} \\ \text { MRR } & \text { Moisture removal rate in } \mathrm{kg} / \mathrm{h} \\ \dot{m}_{\text {sol }} & \text { mass flow rate of solution in } \mathrm{kg} / \mathrm{s} \\ \varepsilon_{d} & \text { Dehumidification effectiveness }\end{array}$

\section{INTRODUCTION}

Humidity control is recognized as a vital issue in industrial, agricultural, and residential sectors specifically in hot and humid climates. Conventional vapor compression systems for air conditioning consumes most of its input power to handle the latent heat load. Also the refrigerants like HFCs have negative impacts on environment(Chen et al. 2019). The air conditioning load can be reduced about to $3-20 \%$ by incorporating insulations over the roof and wall. But the reduction in humidity in the building is not possible with these passive measures (Shwehdi et al. 2015). The limitations associated with vapor compression systems urged researchers to survey new alternative technologies, which are environment-friendly, energy efficient and promising technologies for air conditioning applications. Over the years, liquid desiccant systems have gained significant interest as they utilize the desiccant material a hygroscopic substance to dehumidify the air and provide favorable comfort conditions by improving the indoor air quality while reducing the power consumption of vapor compression air conditioners specifically. Liquid desiccant systems are more promising than solid desiccant systems as they provide more advantages and control flexibility over solid desiccants (Shehadi 2018). Many works related to liquid desiccant system integration with other conventional systems has been reported that C.O.P of the combined systems is found to be increased (Yamaguchi et al. 2011). The internally cooled counter flow dehumidifier offers better dehumidification ability than adiabatic systems. The internally cooled system shows the higher dehumidification efficiency at lower solution flow rates whereas adiabatic system shows 
better performance in larger solution flow rates (Liu, Liu, and Zhang 2019). $\mathrm{LiCl}$ and $\mathrm{LiBr}$ solutions show the higher dehumidification ability but are expensive. Cost effective desiccants like Magnesium chloride $\mathrm{MgCl}_{2}$ and Calcium chloride $\mathrm{CaCl}_{2}$ solutions are able to dehumidify the air to considerable extent. Alternatives like $\mathrm{HCO}_{2} \mathrm{~K}, \mathrm{Ca}\left(\mathrm{NO}_{3}\right)_{2}$ and $\mathrm{H}_{2} \mathrm{PO}_{2}$ provide better dehumidification performance and are less corrosive (Giampieri et al. 2018). Experimental results indicated that $70.3 \% \mathrm{HCO}_{2} \mathrm{~K}$ solution had almost the same vapor pressure as $35 \% \mathrm{LiCl}$ solution but absolute moisture removal of $\mathrm{HCO}_{2} \mathrm{~K}$ solution was found be slightly higher than $\mathrm{LiCl}$ solution and the proposed correlation mentioned will be valuable for the application of $\mathrm{HCO}_{2} \mathrm{~K}$ solution in any LDCS (Wen et al. 2021). Additionally, the thermal properties including the density and vapor pressure of $\mathrm{HCO}_{2} \mathrm{~K}$ solution were measured and fitted as polynomials and the obtained data will be helpful for studying the performance of dehumidifier/regenerator utilizing $\mathrm{HCO}_{2} \mathrm{~K}$ solution.(Wen et al.2019). A proposed polymer hollow fibre integrated desiccant dehumidification system was experimentally investigated and showed comparable dehumidification performance with respect to other porous media integrated liquid desiccant dehumidification system using potassium format (Chen et al. 2018). The effect of various operating inlet parameters on the outlet and performance parameters for the Celdek packed dehumidifier using calcium chloride as desiccant is investigated experimentally and found that the dehumidification performance of the system is affected by solution and air flow rates significantly (Kumar and Asati 2016). Optimization algorithms namely Genetic algorithm, simulated annealing, geometric programming, and particle swarm optimization are studied for a cost saving objective, where Genetic algorithm and particle swarm optimization provides better optimal solutions. Such algorithms also can be applied for liquid desiccant technology to find the optimum operating parameters in energy saving aspect (Ubeku and Odiase 2014). Thermal flume simulations study performed in high rise building for a VRF air conditioning system. The temperatures and air distribution at different locations are found by the simulation study. Such simulations can be effective in examining the performance of liquid desiccant system for predicting the temperature and velocity distribution inside the dehumidifier (Zhang et al.2019). The exergy analysis is performed in air conditioning system with different refrigerants, where the exergy efficiency is increased to $13.2 \%$ when R404 A is replaced with R600A. The exergy analysis also can be performed for liquid desiccant systems to evaluate the actual performance and exergy destruction of the system (Ozbek 2016). The parabolic trough type concentrated solar collector in a small scale is studied with different thermal fluids such as 
therminol, dowtherm and paratherm etc., to evaluate the heat transfer effectiveness. The use of such heat transfer fluid can improve the performance of liquid desiccant system. Particularly liquid desiccant regeneration unit can be integrated with solar collectors with these effective heat transfer fluids (Ullah et al. 2021). Solar based desalination is studied in the plate type collector associated with air flow enhancement. Where the study implies that counter current air flow enhances the desalination performance about 30\%. Moreover, the recycling of condensed air improves the performance about 3.6 times. Since the desalination process is similar to that of liquid desiccant regeneration process, the study helps in understanding the effect of air flow (Mousa and Mjalli 2018). The recent numerical study of spray type liquid desiccant system reported that increase in solution flow rate and decrease in air flow rate improves the specific moisture removal. But when the moisture removal increases, the temperature rise in the air and solution also increases which can be avoided by adding cooling system (Ijas et al. 2021). The literature study implies that there is a lot of scope to utilize the liquid desiccant system in dehumidification and air conditioning applications. Recent studies mentioned that potassium format as one of the ecofriendly well performing liquid desiccants. At the same time more studies required to address the performance of the liquid desiccant system with potassium format. Hence, this study aims to evaluate the dehumidification performance of the aqueous potassium format solution experimentally and to find the effect of flow rates of the air and desiccant solution.

\section{EXPERIMENTAL METHODOLOGY}

An experimental study is performed on liquid desiccant system to study the effect of mass flow rates of air and desiccant solution on dehumidification performance. An existing experimental setup is being used which is installed in hydraulics lab NIT Calicut, Kerala India. The study is aimed to perform only dehumidification performance. So, there is no cooling system incorporated with the liquid desiccant system. The testing is done under the climatic condition of the location where the setup is installed, which is a warm humid outdoor condition. The details of experimental setup and study parameters are explained in following sections.

\section{EXPERIMENTAL SETUP DETAILS AND WORKING PRINCIPLE}

The Figure 1.a shows the schematic diagram of the experimental setup and the Fig.1.b shows the photographic view of the setup. The Experimental setup is a counter flow packed type dehumidifier. The entire dehumidifier body is made of GI sheet. Inside the dehumidifier body, the 
structured packing made of ABS (Acrylonitrile butadiene styrene) is provided as replaceable. The air inlet is provided at the bottom of packing and the outlet is located at the top of the packing. The solution inlet is provided as spray type at the top of the dehumidifier packing and the outlet is provided at the bottom. A dual inlet single outlet variable flow blower $(310 \mathrm{~W})$ is fitted at the inlet to supply the air to the system. The blower speed can be varied such that air flow rate will vary from 350 - 550 CFM. Similarly, a non-corrosive submersible pump (40 W) is provided to supply the liquid desiccant solution. A ball valve is provided to control the solution flow rate. Two plastic tanks (25 liters each) are provided to store the strong solution and collect the weak liquid desiccant respectively. The strong liquid desiccant is supplied by the pump to the top of the dehumidifier packing through the sprayers. The liquid is sprayed over the packing. Meanwhile the outdoor humid air is sent through the blower from the bottom of the packing. The air and solution interact o the surface of the structured packing. Due to the water vapor pressure difference between the solution and the humid air, the moisture from the humid air transfers to the solution. The dehumidified air leaves the dehumidifier at the outlet. During the dehumidification, solution becomes weak due to absorption of the moisture.

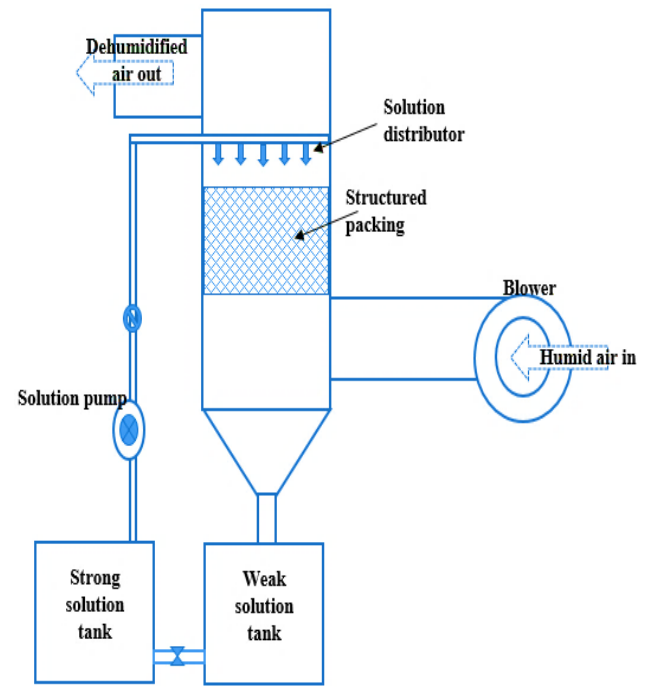

Figure 1a Schematic diagram of the experimental setup

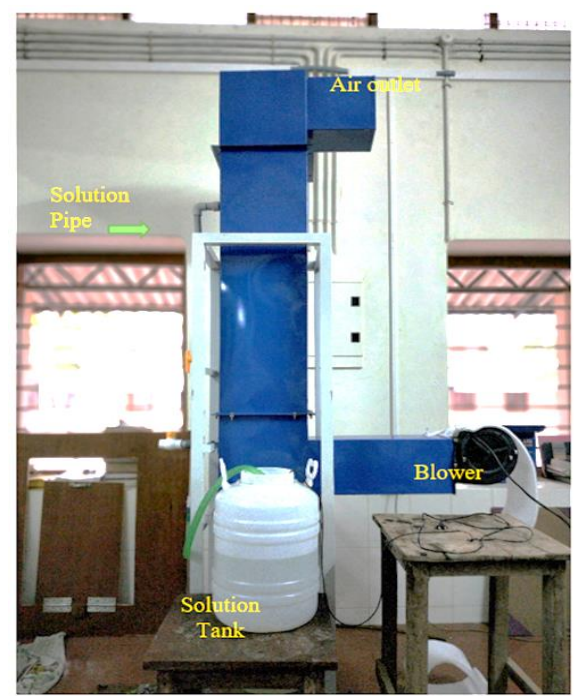

Figure 1b Photographic view of the experimental setup

The weakened solution is being collected in the tank which is provided at the bottom of the dehumidifier. During the process of dehumidification there will be a slight increment in 
temperature of solution. This is due to exothermic reaction by absorbing the moisture. The weakened solution can be regenerated with the same system to concentrate it and the concentrated strong solution can be stored in storage tank and it can be used for further dehumidification cycle. The temperature, humidity and velocity of the air and the temperature, flow rate and concentration of the solution are measured as the primary parameters. The instrument details are provided in the Table 1.

Table 1 Instrument used and operating ranges, accuracy and resolution of the instrument

\begin{tabular}{|l|l|l|l|l|}
\hline Instrument & Parameter & Range & Accuracy & Resolution \\
\hline & Temperature & $0-50^{\circ} \mathrm{C}$ & $\pm 0.6^{\circ} \mathrm{C}$ & $0.1^{\circ} \mathrm{C}$ \\
\cline { 2 - 5 } & $\begin{array}{l}\text { Relative } \\
\text { humidity }\end{array}$ & $0-100 \%$ & $\pm 1.8 \%$ & $0.1 \%$ \\
\hline $\begin{array}{l}\text { Testo } 480 \\
\text { Anemometer }\end{array}$ & Velocity & $0-20 \mathrm{~m} / \mathrm{s}$ & $\pm 0.03 \mathrm{~m} / \mathrm{s}$ & $0.01 \mathrm{~m} / \mathrm{s}$ \\
\hline Hydrometer & Specific gravity & $1-2$ & \pm 0.1 & 0.1 \\
\hline
\end{tabular}

The vapor pressure of aqueous potassium format solution is calculated by the following equation provided by (Longo and Fedele 2018)

$\ln (p)=\left(17.864+2.7856 / T-2.564 / T^{2}\right)+\left(-3659.7-306.42 / T-812.21 / T^{2}\right) \cdot X+$

$\left(249986.0+93118.0 / T+24973.0 / T^{2}\right) \cdot X^{2}$

where, $p$ - the vapour pressure of the solution in mbar; $T$ - temperature of the solution in $K$; $X$ the salt mass fraction;

\section{PERFORMANCE PARAMETERS TO BE STUDIED}

The following parameters are evaluated to define the performance of dehumidification.

Specific humidity change $(\Delta w)$ : The difference of humidity ratio of the air between entering and leaving the dehumidifier ( $\mathrm{g} / \mathrm{kg}$ of dry air).

$$
\Delta w=w_{\text {in }}-w_{\text {out }}
$$

Dehumidification effectiveness $\left(\varepsilon_{\boldsymbol{d}}\right)$ : Ratio of actual moisture removed to the maximum moisture can be removed by the liquid desiccant.

$$
\varepsilon_{d}=\frac{w_{\text {in }}-w_{o u t}}{w_{\text {in }}-w_{e q}}
$$


The term $w_{e q}$ is equilibrium humidity ratio is calculated as a function of vapour pressure of the liquid at particular solution concentration and temperature.

$$
w_{e q}=0.622 * \frac{P_{\text {sol }\left(X, T_{\text {sol }}\right)}}{P_{a t m}-P_{\text {sol }\left(X, T_{\text {sol }}\right)}} \mathrm{kg} / \mathrm{kg} \text { of dry air }
$$

Moisture removal rate $(\mathbf{M R R})(\mathrm{kg} / \mathrm{h})$ : Amount moisture removed from the air per hour. This value tells the actual moisture removed from the air over a period.

$$
M R R=\left[\dot{m}_{\text {air }}\left(w_{\text {in }}-w_{\text {out }}\right)\right] \times 3600 \mathrm{~kg} / \mathrm{h}
$$

Latent heat removal capacity $(\mathrm{kW})$ : The heat removed due to removing moisture from the air is called as latent heat removal capacity.

$$
Q_{\text {latent }}=\dot{m}_{w} h_{f g} \quad \text { or }\left[\dot{m}_{\text {air }}\left(h_{\text {in }}-h_{\text {out }}\right)\right] \mathrm{kW}
$$

$h_{f g}$ is the latent heat of fusion of the water vapor at dry bulb temperature of air. The $h_{\text {in }}$ and $h_{\text {out }}$ are the enthalpies of air at taken inlet and outlet of the dehumidifier respectively.

These parameters are evaluated by varying the mass flow rate of air and solution flow rates when other operating conditions maintained as constants. The range of operating parameters and constant values are given in the Table 2 .

Table 2 Operating Parameters

\begin{tabular}{|l|l|l|}
\hline Parameters to be varied & Range & Reference value of the constant parameters \\
\hline & & DBT $=29^{\circ} \mathrm{C} \pm 1^{\circ} \mathrm{C}$ \\
& & $\mathrm{W}_{\mathrm{in}}=19 \mathrm{~g} / \mathrm{kg}$ of dry air $\pm 1 \mathrm{~g} / \mathrm{kg}$ of dry air \\
\cline { 3 - 4 } & $\mathrm{T}_{\mathrm{sol}}=30^{\circ} \mathrm{C} \pm 1^{\circ} \mathrm{C}$ \\
\cline { 3 - 4 } & $\mathrm{C}_{\mathrm{sol}}=68 \% \pm 0.5 \%$ \\
\hline
\end{tabular}




\section{UNCERTAINTY ANALYSIS}

The uncertainty analysis is evaluated for the sample experiment readings using Propagation analysis method(Moffat 1988).If $a=f\left(x_{1}, x_{2} \ldots x_{n}\right)$; where $x_{1,}, x_{2}, \ldots x_{n}$ are the independent variables and $\partial c_{1}, \partial c_{2} \ldots \ldots \partial c_{n}$ are the uncertainty of independent variables respectively. The resultant uncertainty $\left(\mathrm{a}_{\mathrm{x}}\right)$ can be calculated by the following formula.

$$
\mathrm{a}_{\mathrm{x}}=\sqrt{\left(\frac{\partial c_{1}}{\partial x_{1}}\right)^{2} \cdot \Delta a^{2}+\left(\frac{\partial c_{2}}{\partial x_{2}}\right)^{2} \cdot \Delta a^{2}+\cdots\left(\frac{\partial c_{n}}{\partial x_{n}}\right)^{2} \cdot \Delta a^{2}}
$$

The calculated uncertainty values are provided in the Table 3

Table 3: Uncertainty errors of the results

\begin{tabular}{|l|l|l|}
\hline S.No & Parameters & Uncertainty \\
\hline 1. & Temperature & $\pm 0.6^{\circ} \mathrm{C}$ \\
\hline 2. & Relative humidity & $\pm 1.8 \%$ \\
\hline 3. & Velocity & $\pm 0.03 \mathrm{~m} / \mathrm{s}$ \\
\hline 4. & Specific humidity & $\pm 0.615 \mathrm{~g} / \mathrm{kg}$ of dry air \\
\hline 5. & MRR & $\pm 0.12 \mathrm{~g} / \mathrm{s}$ \\
\hline 6. & Effectiveness & \pm 0.004 \\
\hline
\end{tabular}

\section{RESULTS AND DISCUSSIONS:}

The sample readings from the experimentation is provide in the Table 4 . The table shows the values of specific moisture change $(\Delta w)$ ranges from 2.6 to $4.2 \mathrm{~g} / \mathrm{kg}$ of dry air. Other dehumidification performance parameters are also evaluated and the effect of mass flow rates of air and solution on these parameters is discussed in this section. 
Table 4 Sample Readings

\begin{tabular}{|c|c|c|c|c|c|c|c|c|c|c|c|}
\hline $\begin{array}{c}\mathbf{T}_{\text {air in }} \\
{ }^{\circ} \mathbf{C}\end{array}$ & R.H. ${ }_{\text {in }} \%$ & $\begin{array}{l}m_{\text {air }} \\
\mathrm{kg} / \mathrm{s}\end{array}$ & $\begin{array}{c}\mathbf{m}_{\text {sol }} \\
\mathrm{kg} / \mathrm{s}\end{array}$ & $\begin{array}{c}\mathbf{T}_{\text {sol in }} \\
{ }^{\circ} \mathbf{C}\end{array}$ & $\mathrm{C}_{\mathrm{sol}} \%$ & $\begin{array}{c}w_{\text {eq }} \\
\text { g/kg } \\
\text { dry } \\
\text { dry }\end{array}$ & $\begin{array}{c}\mathbf{T}_{\text {air out }} \\
{ }^{\circ} \mathbf{C}\end{array}$ & R.H. $_{\text {out }} \%$ & $\begin{array}{c}w_{\text {in }} \text { g/kg } \\
\text { of dry } \\
\text { air }\end{array}$ & $\begin{array}{c}w_{\text {out }} \mathrm{g} / \mathrm{kg} \\
\text { of dry } \\
\text { air }\end{array}$ & $\begin{array}{c}\Delta w \\
\text { g/kg of } \\
\text { dry air }\end{array}$ \\
\hline 29.4 & 75.5 & 0.187 & 0.115 & 29.1 & 70 & 9.8 & 29.6 & 59 & 19.6 & 15.4 & 4.2 \\
\hline 29.8 & 72.6 & 0.187 & 0.093 & 29.2 & 69.8 & 9.7 & 30.4 & 56.6 & 19.3 & 15.5 & 3.8 \\
\hline 29.8 & 73 & 0.187 & 0.055 & 30.2 & 69.5 & 10.0 & 31.5 & 54 & 19.4 & 15.7 & 3.6 \\
\hline 29.9 & 73.9 & 0.225 & 0.115 & 30.1 & 69 & 11.0 & 31.9 & 54.2 & 19.8 & 16.2 & 3.6 \\
\hline 29.8 & 74.2 & 0.225 & 0.093 & 29 & 71 & 9.6 & 30.6 & 58.7 & 19.7 & 16.3 & 3.4 \\
\hline 29.4 & 74.8 & 0.225 & 0.055 & 29.1 & 71.5 & 9.8 & 29.8 & 61.9 & 19.6 & 16.4 & 3.2 \\
\hline 29.5 & 71.8 & 0.272 & 0.115 & 30.2 & 70.8 & 9.1 & 30.7 & 56.8 & 18.9 & 15.8 & 3.1 \\
\hline 30.2 & 70.9 & 0.272 & 0.093 & 30.1 & 70 & 9.3 & 31.2 & 58.3 & 19.5 & 16.7 & 2.8 \\
\hline 29.1 & 76.2 & 0.272 & 0.055 & 30.3 & 71 & 9.4 & 30.9 & 60.8 & 19.8 & 17.2 & 2.6 \\
\hline
\end{tabular}

The Figure 2 shows the specific humidity change with the variation in solution flow rate and air flow rate. The $\Delta w$ is increasing with the increase in solution flow rate but decreases with the increase in air flow rate. Also, from the Figure 2 it is understood $\Delta w$ decreases with increase in airflow rate for a single constant flowrate. Because at lower air flow rates, air gets enough time to interact with the solution. So the $\Delta w$ reaches higher values in lower air flow rates. Since the solution is the moisture absorbing medium, the $\Delta w$ keeps increasing with the increase in solution flow rates. The maximum $\Delta w$ reaches up to $4.2 \mathrm{~g} / \mathrm{kg}$ of dry air when a solution flow rate its maximum $(0.115 \mathrm{~kg} / \mathrm{s})$ and air flow rate at its minimum value $(0.187 \mathrm{~kg} / \mathrm{s})$ 
The Figure 3 shows the moisture removal rate performance with the variation of air and solution flow rates. The moisture removal rate is the actual amount of moisture removed from the air during dehumidification over a time. Basically, MRR is a function of air flow rate, so the MRR has the increasing trend with increase in air flow rate. Since the MRR is a product of both air flow rate and $\Delta w$, some cases the variation of MRR depends upon the $\Delta w$ also. But in higher air flow rate with the higher air solution flow rate MRR reaches the higher value up to $3.1 \mathrm{~kg} / \mathrm{h}$. So, the solution flow rate has the significant part in affecting the moisture removal rate also.

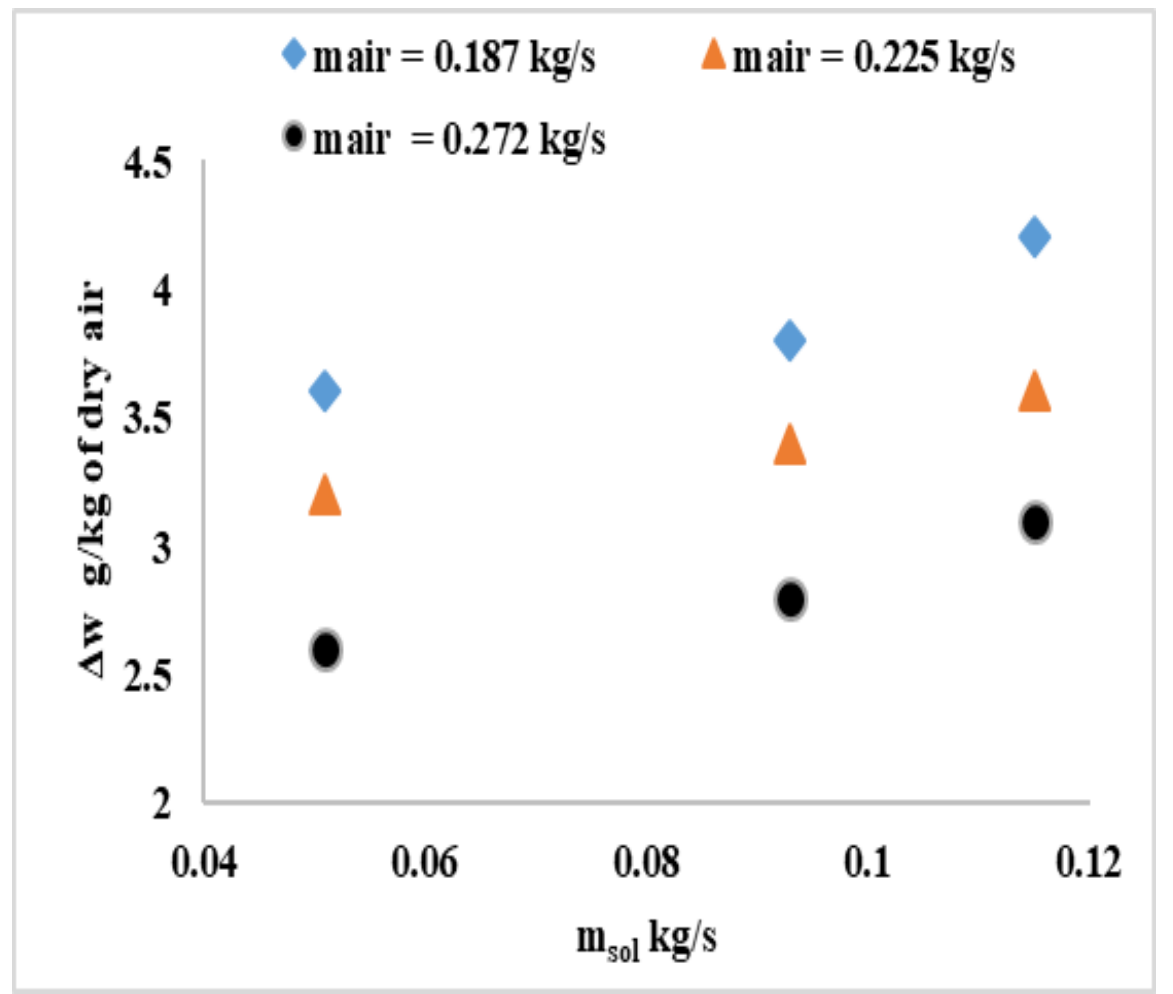

Figure 2 Specific moisture change $(\Delta w)$ 


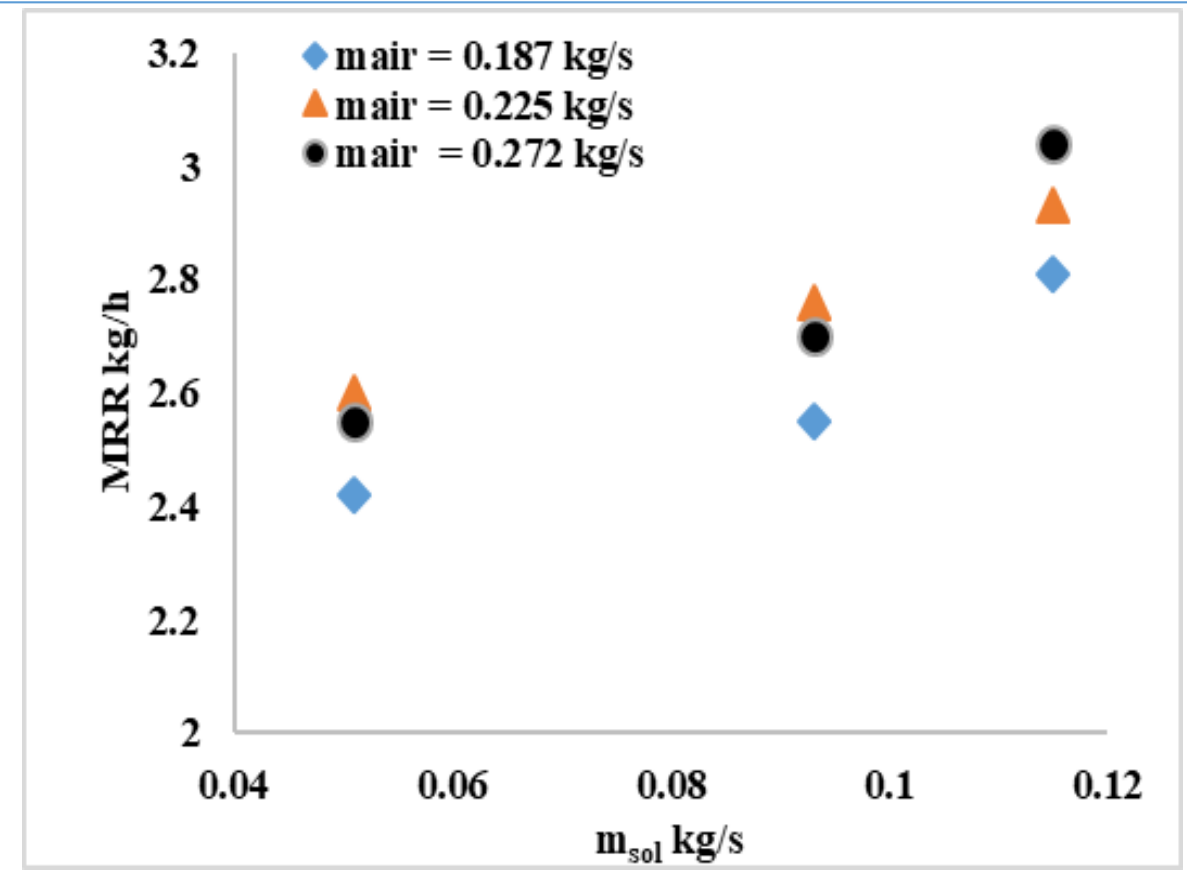

Figure 3 Moisture removal rate (MRR)

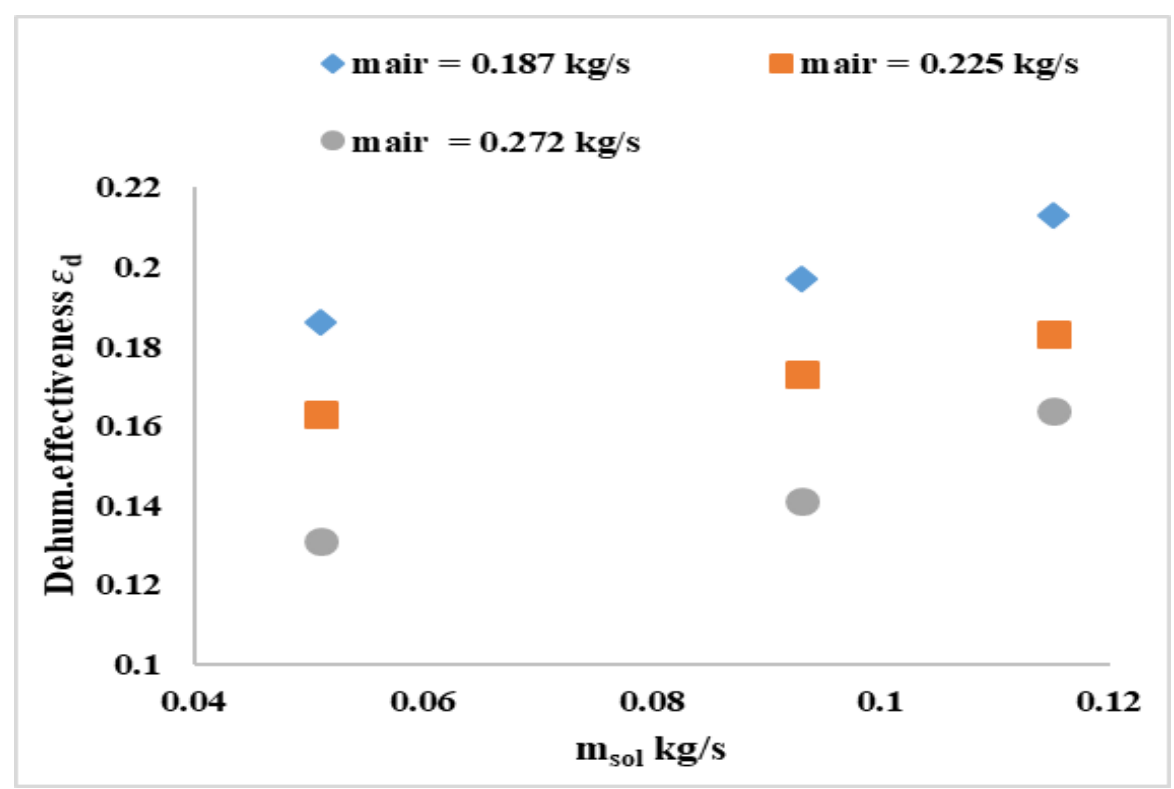

Figure 4 Dehumidification effectiveness

The Figure 5 shows the dehumidification effectiveness of the system with respect to solution and air flow rates. Dehumidification effectiveness is the ratio of the actual dehumidification to the maximum possible dehumidification. The system shows the effectiveness within the range of 0.12 to 0.21 . the effectiveness is following the similar trend like $\Delta w$ as it is a direct function of specific moisture change. So in similar way like $\Delta w$ the effectiveness increase with the solution flow rate 
and decreases with the increase in air flow rate. Since the cooling system is not incorporated the effectiveness is not up to the mark. The effectiveness is also depending on other parameters such as packing type spraying and distribution of solution. So there is further scope to improve effectiveness by improving the design of the system.

The effect of mass flow rates of air and solution on latent heat removed shown in Figure 5.the latent heat removed is the heat removed by removal of moisture from the air. The latent heat is evaluated without accounting the sensible heat during the dehumidification. Since the latent heat removal is a function of MRR it follows the similar trend with the variation of flow rates of air and solution. The latent heat removal increases with both solution and air flow rate. The latent heat value reaches up to $2.1 \mathrm{~kW}$ for an air flow rate of $0.272 \mathrm{~kg} / \mathrm{s}$ (550 CFM), which is equal to $0.6 \mathrm{TR}$ of cooling capacity. Still at the same time there is a temperature rise in air up to $2^{\circ} \mathrm{C}$ due to exothermic reaction of solution during moisture absorption. The heat can be addressed as sensible heat added during the process of dehumidification. Anyway, this temperature rise can be eliminated when the solution is used at low temperatures or by incorporating a dedicated cooling systems such as vapour compression refrigeration or evaporative cooling systems.

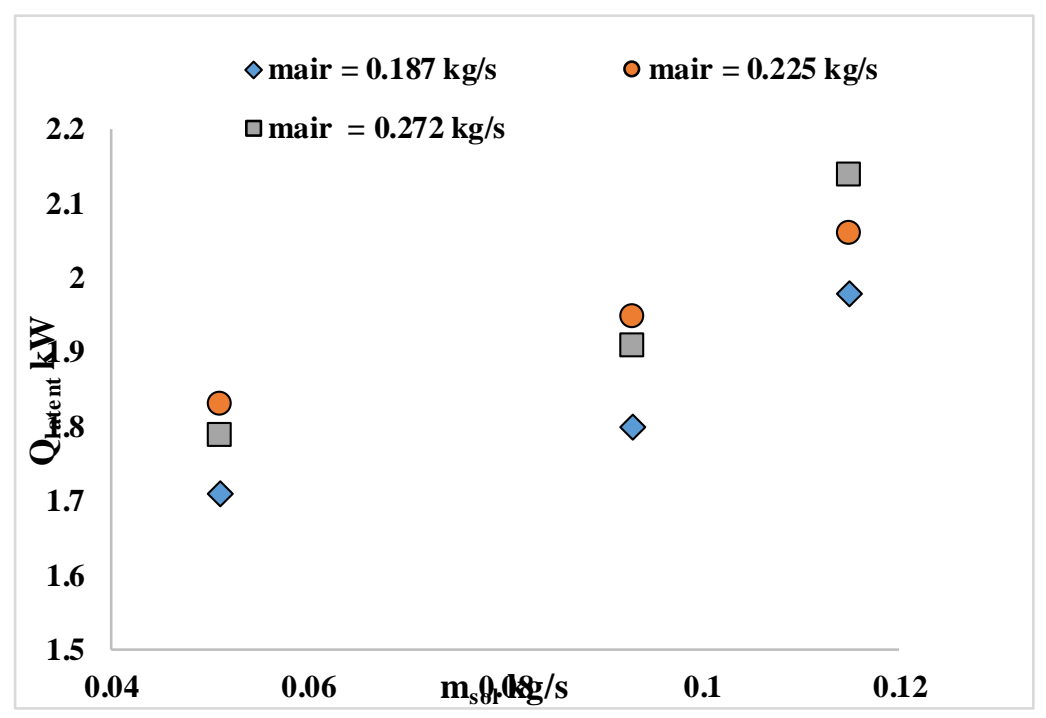

Figure 5 Latent heat removal capacity $\left(Q_{\text {latent }}\right)$ 


\section{CONCLUSION}

The main purpose of the study is to evaluate the dehumidification performance of the liquid desiccant system with aqueous $\mathrm{HCO}_{2} \mathrm{~K}$. The experimentation is done on structured packing counter-flow type dehumidifier. Mainly this study aimed to evaluate the dehumidification performance under the effect of solution flow rate and air flow rate variations. The following points are inferred from the current study. The specific moisture change $(\Delta w)$, which is the primary parameter of dehumidification performance, reached up to $4.2 \mathrm{~g} / \mathrm{kg}$ of dry air. The $\Delta w$ increases with the increase in solution flow rate but decreases with increase in air flow rate. This is due to the reason that, at lower air flow rates there is sufficient time for interaction of air with the solution which leads in good moisture transfer from air to solution. Particularly the $\Delta w$ reaches the maximum value $(4.2 \mathrm{~g} / \mathrm{kg}$ of dry air) at lowest air flow rate $(0.187 \mathrm{~kg} / \mathrm{s})$ and highest solution flow rate $(0.115 \mathrm{~kg} / \mathrm{s})$. The moisture removal rate is directly proportion to the mass flow rate of the air. But in some cases the moisture removal rate is lesser for the air flow rate $0.272 \mathrm{~kg} / \mathrm{s}$ than that of $0.225 \mathrm{~kg} / \mathrm{s}$. This is due to the reason that at lower air flow rates the specific moisture change is better than higher air flow rates. So the specific moisture change is dominating in low er airflow rates. But when solution flow rate increases the MRR keep increases. At higher solution flow rate with higher air flow rate MRR reaches the maximum value of $3.1 \mathrm{~kg} / \mathrm{h}$. So, the increase in solution flow rate always increasing the moisture removal performance. The dehumidification effectiveness follows similar trend like specific moisture change $(\Delta w)$ as it is a direct function of $\Delta w$. The effectiveness increases with the solution flow rate and decreases with air flow rate. The effectiveness lies in the range between 0.12 to 0.21 . The effectiveness can be further improved with incorporating a solution cooling system. The latent heat removed is discussed which is evaluated without accounting the sensible heat added during dehumidification. The latent heat removal capacity $\left(Q_{\text {latent }}\right)$ following a similar trend of moisture removal rate. The $Q_{\text {latent }}$ increases with the increase in both solution flow rate and air flow rate. $Q_{\text {latent }}$ reaches up to 2.1 $\mathrm{kW}$ which is a significant value without cooling system. Anyway, the sensible heat addition is not accounted here, by adding a cooling system the sensible heat can also be reduced and latent heat removal capacity can be further improved. Overall, the studied liquid desiccant dehumidification system with aqueous potassium format shows a significant dehumidification performance. The 
system still has the scope to improve the performance by adding the cooling system. The results particularly the latent heat removal shows feasibility that the system can be extended as an air conditioning system by incorporating a vapor compression or any other conventional cooling system.

\section{REFERENCES}

Chen, Xiangjie, Saffa Riffat, Bai Hongyu, Xiaofeng Zheng, and David Reay. 2019. "Recent Progress in Liquid Desiccant Dehumidification and Air-Conditioning: A Review." Energy and Built Environment, October. https://doi.org/10.1016/J.ENBENV.2019.09.001.

Chen, Xiangjie, Yuehong Su, Devrim Aydin, Hongyu Bai, Hasila Jarimi, Xingxing Zhang, and Saffa Riffat. 2018. "Experimental Investigation of a Polymer Hollow Fibre Integrated Liquid Desiccant Dehumidification System with Aqueous Potassium Formate Solution.” $\begin{array}{lllll}\text { Applied } & \text { Thermal } & \text { Engineering } & \text { 632-43. }\end{array}$ https://doi.org/10.1016/J.APPLTHERMALENG.2018.07.003.

Giampieri, Alessandro, Zhiwei Ma, Andrew Smallbone, and Anthony Paul Roskilly. 2018. "Thermodynamics and Economics of Liquid Desiccants for Heating, Ventilation and AirConditioning - An Overview." Applied Energy 220 (June): 455-79. https://doi.org/10.1016/J.APENERGY.2018.03.112.

Ijas Ahmed, M., R. Vignesh, and L. Gangadhara Kiran Kumar. 2021. "Computational Analysis of Spray Type Counter Flow Liquid Desiccant Dehumidifier." Materials Today: Proceedings, January. https://doi.org/10.1016/j.matpr.2020.10.888.

Kumar, Rakesh, and A. K. Asati. 2016. "Experimental Study on Performance of Celdek Packed Liquid Desiccant Dehumidifier.” Heat and Mass Transfer/Waerme- Und Stoffuebertragung 52 (9): 1821-32. https://doi.org/10.1007/s00231-015-1704-2.

Liu, Jun, Xiaohua Liu, and Tao Zhang. 2019. "Comparison of Internally Cooled and Adiabatic Liquid Desiccant Dehumidification-Regeneration System.” Building and Environment 163 (October): 106313. https://doi.org/10.1016/J.BUILDENV.2019.106313.

Longo, Giovanni A., and Laura Fedele. 2018. "Experimental Measurement of Equilibrium Vapour Pressure of $\mathrm{H} 2 \mathrm{O} / \mathrm{KCOOH}$ (Potassium Formate) Solution at High Concentration.” International Journal of Refrigeration 93 (September): 176-83. 
https://doi.org/10.1016/J.IJREFRIG.2018.06.015.

Moffat, Robert J. 1988. "Describing the Uncertainties in Experimental Results." Experimental Thermal and Fluid Science 1 (1): 3-17. https://doi.org/10.1016/0894-1777(88)90043-X.

Mousa, Hasan, and Farouq S Mjalli. 2018. "Solar Water Desalination Using Plate-like Desalination Unit Enhanced by Air Flow." Journal of Engineering Research. Vol. 6. https://kuwaitjournals.org/jer/index.php/JER/artie/view/5067.

Ozbek, Arif. 2016. "Energy and Exergy Analysis of a Ceiling Type Air Conditioning System Operating with Different Refrigerants." Journal of Engineering Research 4 (3). https://kuwaitjournals.org/jer/index.php/JER/article/view/1055.

Shehadi, Maher. 2018. "Review of Humidity Control Technologies in Buildings." Journal of $\begin{array}{llll}\text { Building } & \text { Engineering } & 19 & \text { (September): }\end{array}$ https://doi.org/10.1016/J.JOBE.2018.06.009.

Shwehdi, M. H, S. Rajamohamed, A. Ali Smadi, M. Bouzguenda, A. A. Alnaim, and S. Fortea. 2015. "Energy Savings Approaches of Buildings in Hot-Arid Region, Saudi Arabia: Case Study." Journal of Engineering Research 3 (1). https://kuwaitjournals.org/jer/index.php/JER/article/view/377.

Ubeku, Ubiomo Emmanuel, and Friday Osasere Odiase. 2014. "A Comparative Analysis of Multi-Objective and Multialgorithm Approaches for the Optimal Design of Distribution Transformers." Journal of Engineering Research 2 (4). https://kuwaitjournals.org/jer/index.php/JER/article/view/252.

Ullah, Ahmed, Asim Mushtaq, Rizwan Ahmed Qamar, and Zaeem Uddin Ali. 2021. "Performance Analysis and Modeling of Parabolic Trough Based Concentrated Solar Facility Using Different Thermal Fluid Mediums.” Journal of Engineering Research 9 (1): 13-50. https://doi.org/10.36909/jer.v9i1.8605.

Wen, Tao, Yimo Luo, Meng Wang, and Xiaohui She. 2021. "Comparative Study on the Liquid Desiccant Dehumidification Performance of Lithium Chloride and Potassium Formate." Renewable Energy 167 (April): 841-52. https://doi.org/10.1016/j.renene.2020.11.157.

Wen, Tao, Meng Wang, Yi Chen, Weifeng He, and Yimo Luo. 2019. “Thermal Properties Study and Performance Investigation of Potassium Formate Solution in a Falling Film 
Dehumidifier/Regenerator." International Journal of Heat and Mass Transfer 134 (May): 131-42. https://doi.org/10.1016/j.ijheatmasstransfer.2019.01.031.

Yamaguchi, Seiichi, Jongsoo Jeong, Kiyoshi Saito, Hikoo Miyauchi, and Masatoshi Harada. 2011. "Hybrid Liquid Desiccant Air-Conditioning System: Experiments and Simulations." In Applied Thermal Engineering, 31:3741-47. Pergamon. https://doi.org/10.1016/j.applthermaleng.2011.04.009.

Zhang, Yin, Xiao Zhang, Shurui Guo, and Enshen Long. 2019. "Thermal Plume Simulation of VRF Air Conditioners for Cooling System in High-Rise Buildings: A Case Study in China." $\begin{array}{lllll}\text { Journal of } & \text { Engineering } & \text { Research. } & \text { Vol. } & 7 .\end{array}$ https://kuwaitjournals.org/jer/index.php/JER/article/view/4250. 